\title{
Pedagogical expediency of using computer technologies in the process of teaching Mathematics in a humanitarian university
}

\author{
E.V. Vezetiu' ${ }^{1 *}, J u . V$. Makarenko ${ }^{2}$, and Z.I. Bazhan ${ }^{3}$ \\ ${ }^{1}$ V.I. Vernadsky Crimean Federal University, Simferopol, Russia \\ ${ }^{2}$ V.I. Vernadsky Crimean Federal University, Simferopol, Russia \\ ${ }^{3}$ V.I. Vernadsky Crimean Federal University, Simferopol, Russia
}

\begin{abstract}
The article reveals the problem of teaching Mathematics in humanitarian higher educational institutions that teach students in the context of new educational standards and reducing the time allocated for research in this discipline. The results of the introduction at the university of an educational and methodological complex based on a combination of contact work with students and distance learning methods supported with modern systems. The article confirms the need of finding effective ways of organizing the learning process, reviewing the structure and careful selection of the content of students' training in Mathematics. The scientific novelty of the research is a factor that determines the pedagogical expediency of achieving the ability to use the means of computer technology in the educational process in Mathematics in universities.
\end{abstract}

\section{A problem statement}

The urgency of the research topic is due to the fact that one of the main tasks of higher education in Russia is the preparation of highly qualified specialists with basic scientific knowledge and applied skills in the field of expertise. This also applies to mathematical training, which is very important for many areas, not only technical, but also humanitarian. According to the program of the development and modernization of mathematical education in Russia, Mathematics should occupy a special place in Russian science and public life and be one of the most important components of scientific and technological progress [1]. The concept of development of mathematical education in the Russian Federation emphasizes: "Without a high level of mathematical education, it is impossible to fulfill the task of creating an innovative economy, achieving long-term goals of socioeconomic development of the Russian Federation and the state ..." [2].

In accordance with the Federal State Standards of Higher Professional Education, every graduate of the humanitarian direction must have professional competence, including possessing mathematical research methods in his area of professional activity. That is why

\footnotetext{
* Corresponding author: prof-ped.gpa@mail.ru
} 
in conditions of the absence of training in methods of mathematical modeling, it is impossible to imagine the training of graduates of humanitarian specialties.

The implementation of this concept could provide a new level of mathematical education for higher educational institutions. However, setting such an important task of higher education, teachers and students face many problems in the process of interaction, because the number of classroom hours in a university is passed from generation to generation in all subjects, which ultimately formalizes the learning progress in the form of acquired professional and general cultural skills - the so-called hard skills (professional skills related to the field of activity) and soft skills (general skills required for the development of a successful personality in any field of activity). The competence-based approach stimulates the development and implementation of new progressive teaching and pedagogical methods, including distance learning, as well as the development of project work [3].

However, as many years of teaching practice have shown, these methods and techniques are not always effective in teaching mathematical and technical disciplines, especially in humanitarian universities.

Besides, from year to year we observe a decrease in classroom time even in subjects related to mathematics and information training in the humanities and economic courses of general education programs, which is associated with a significant reduction in the number of relevant competencies in the new standards of higher education.

The transition to a competence-based approach in education requires a revision of the entire learning process, since the traditional system of transferring knowledge to students and subsequent assessment of the degree of mastering such knowledge is entirely based on contact work (classroom studies in the form of seminars, testing and exams) and loses its effectiveness. Taking into account the reduction of classroom time, this system does not allow students to master basic mathematical knowledge, since it does not provide the required level of systematic training. At the same time the transition to a new teaching model should be aimed at cultivation the skills of independent acquisition of knowledge in students through the organization of personalized educational and cognitive activities.

Another problem in organizing the process of mathematical education is the basic level of mathematical training of freshmen. It is necessary to take into account the difficulties in the study of Mathematics by students of humanitarian specialties, which in most cases is explained by improper teaching back in school - superficial, without explaining the foundations and patterns of certain mathematical phenomena, by the lack of practical examples and explanations that everyone needs to study, which ultimately creates a fear of the exam and the discipline itself for the whole life.

The study of the elements of mathematical modeling can be included in various modular disciplines:

- "Informatics", "Mathematical Methods of Decision Making";

- "Econometric Modeling", as well as Mathematics in social and humanitarian fields, "Mathematical Methods in Scientific Research";

- "Mathematical Methods in Linguistics", etc.

The study of mathematical models in the humanities has many peculiarities [4].

1. Traditionally students of humanitarian specialties study only the basics of Higher Mathematics. Besides, since 2015, the Unified State Exam in Mathematics (USE) has been divided into two levels: profile and basic. The tasks at the profile level are basically the same as those of the National Unified Exam in previous years. Basic tasks are much easier, considering only the basics of Algebra, Geometry and Analysis. To obtain a certificate of secondary education, you must pass the basic exam with a positive mark. The basic exam is also sufficient for admission to humanitarian educational institutions for such directions as 
philosophy, linguistics, history, jurisprudence, psychology, journalism, political science, cultural studies, etc.

In their turn, many mathematical models are composed of complex mathematical structures. So, for example, a model describing a change in a system is a differential equation of the total derivative or partial derivative. Often a person who is "into humanities" does not know the system of such equations.

2. The mathematical model of the complexity of computer implementation, as a feature of the study of mathematical models in the humanities, is closely related to the previous one.

In order to implement mathematical models on a computer and conduct experiments, it is necessary to use special software, and sometimes methods of computing mathematics, the study of which is usually not provided in the humanities.

3. Students of humanitarian specialties in most cases do not show interest in the study of mathematical disciplines [5]. To master the basics of mathematical modeling successfully, you can provide the following solutions: models using linear algebra and mathematical statistics. The study of these topics of mathematics is less difficult than other sections and their fundamentals are studied even in high school. Spreadsheets (MS Excel, Open Office Calc, Gmuneric) contain a large number of built-in functions for solving linear algebra and statistics problems, and students will be more interested in learning mathematical modeling methods if they use professionally oriented models instead of standard ones. Thus, for the high-quality training of future graduates of humanitarian specialties and increasing their interest in methods of mathematical modeling, it is necessary to choose carefully a professionally oriented teaching model that does not contain too complex mathematical operations.

Summarizing the opinions of the authors [6], we can conclude that the pedagogical expediency of realizing the capabilities of information technology tools in the process of teaching mathematics is determined by instant feedback between the user and information technology tools.

A special role belongs to computer technology, which is used to form important skills of specialists, such as thinking skills, basic computer skills, the ability to acquire new knowledge (not only mathematical) using modern educational and information technologies, research activities, the ability to solve mathematical problems, etc.

The use of computers in teaching should orient students towards self-education, where knowledge, skills and abilities are the result of personal, creative efforts, reflection, etc.

V.A. Slastenin notes that the use of computers in teaching higher mathematics courses will help to teach Mathematics more clearly and deeply, setting students free from a number of ordinary calculations, and teachers from mechanical checking. This will allow students to focus on the nature of the studied models and algorithms [7].

The form of using information technologies in the course of the natural and mathematical cycle is determined by various factors. For example, the topic and objectives of a specific course, the characteristics and functions of the available educational computer programs, etc. Nowadays to master one of the common software packages for automatic calculation, namely the ability to display the results in a graphical form, is necessary for any specialist in the field of natural science or technical review. It should be noted that the universal mathematical system opens up new opportunities for improving education at all stages without exception - from purposeful teaching and upbringing to integrated preparation of students for professional activity and self-realization.

With the development of software, the ability to use applied software packages has become one of the main components of information training for specialists. By making it easier to solve complex problems, they remove psychological barriers to mathematical research and make the process fun and easy. If they are applied correctly in the educational 
process, then these packages can improve the level of basic math education. The use of special computer systems (Mathematica, MathCad, MathLab, SPSS, etc.) contributes to the development of students' mathematical abilities in the learning process. But, unfortunately, many teachers unconsciously resist a radical revision of the content and methods of teaching Mathematics in higher educational institutions.

Today there are a number of ways to use information technology tools in the learning process of Mathematics. However, it must be admitted that the informatization of higher education can give the necessary socio-economic effect only if the created and introduced information technologies do not become an external factor in the traditional system of higher education, but are naturally integrated into it, are combined with traditional teaching methods - "with all the variety of pedagogical methods, the implementation of the leading pedagogical functions remains with the teachers" [8]. Nevertheless, a modern specialist must be a creative person, able to make correct, as a rule, non-standard decisions in difficult situations, to prepare for continuous self-education. The basis for solving these problems is the high-quality mathematical education of university graduates, implemented in the process of applying the competence-based selection of a package of applied math courses in the process of training specialists in Higher Mathematics.

\subsection{The objective of the work}

The experiment, in which 140 students and 10 teachers took part, was carried out on the basis of the Federal State Autonomous Educational Institution of Higher Education "V.I. Vernadsky Crimean Federal University".

The experiment is represented by the following stages:

1) Description.

2) Search engine.

3) Formative stage.

\section{Results of the research}

When determining the course of the experiment, a modification of the method for educational motivation of students was used, which is based on the theory of M.V. Matyukhina.

The analysis of the obtained results showed that students have a high level of professional motivation and a low level of educational and cognitive motivation and creative self-realization (Figure 1).

We identified two experimental groups (EG): H1 (History Department) and P1 (Philology Department). The survey was conducted in the first year of study:

1. Is it easy for you to study at the Federal State Autonomous Educational Institution of Higher Education "V.I. Vernadsky Crimean Federal University"?

2. What subjects do you consider the most difficult (no more than three)?

3. Select the math part that you find most difficult to understand.

4. Did you study trigonometry at school?

5. Which math sections do you think are more appropriate for your future career?

6. Can different teaching methods be used to make trigonometry more accessible?

7. Do you use information technology when studying Mathematics?

8. Do you use other sources on the Internet when studying Mathematics?

9. Do you use additional literature when studying Mathematics?

10. How to achieve the most effective mastering of various parts of Mathematics? 


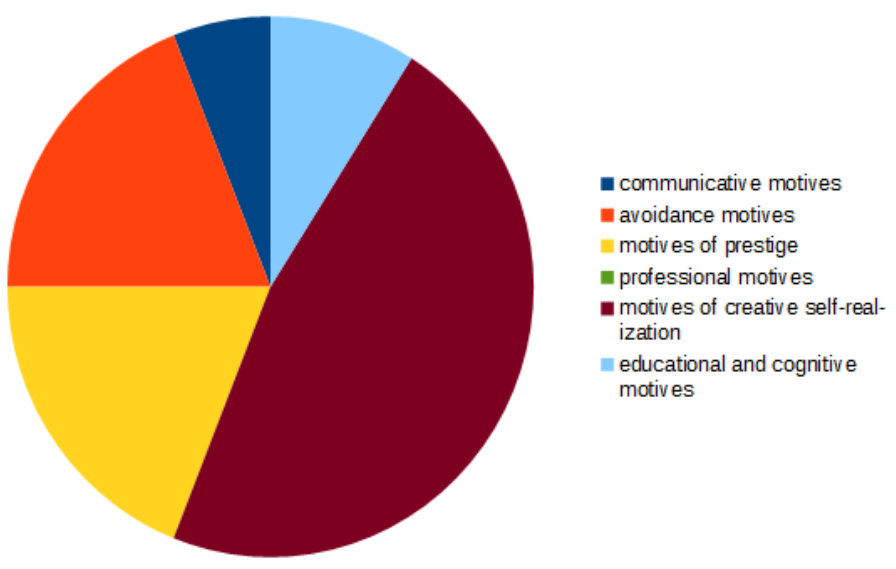

Fig. 1. Analysis of students' motivation.

The analysis of the answers showed the following results: $72 \%$ of students found it very difficult to study at the "V.I. Vernadsky Crimean Federal University"; 83\% of respondents named the Sciences (Mathematics, Physics, Chemistry) the most difficult to study (trigonometry was the most difficult in Mathematics); $85 \%$ of students used information technology (answer books, calculators, presentations) in mathematical research; only 52\% used additional sources on the Internet and $13 \%$ of students needed additional literature. Based on the results of the research, an electronic workbook was created for the section "Trigonometry".

The first-year students' opinions on the implementation of effective assimilation of the mathematical part are as follows: $20 \%$ of students support the introduction of additional courses in mathematics; $31 \%$ - for courses with individual teachers, which allows us to make the following conclusion: FGAOU VO "KFU named after IN AND. Vernadsky" there is not enough classroom time for teachers of the Federal State Autonomous Educational Institution of Higher Education "V.I. Vernadsky Crimean Federal University" for students' training, since most of the time is devoted to independent work. There is a very large gap in the remaining knowledge, to remove which there isn't also enough time. That is why the use of ICT for the correct organization of independent work of students of the Federal State Autonomous Educational Institution of Higher Education "V.I. Vernadsky Crimean Federal University" in Mathematics can satisfy the requirements of teachers and students.

The use of ICT for the organization of independent work of students according to the mathematical method is introduced as an experiment. As a search experiment, the pedagogical experience was analyzed, research hypotheses were formed, and the necessary e-learning tools were created to improve the quality of mathematical education at the "V.I. Vernadsky Crimean Federal University".

The methods used at this stage: observation, analysis of psychological and pedagogical literature, questioning, generalization of pedagogical experience, tests, analysis of experimental results, scaling, mathematical and statistical methods of processing the results obtained, synthesis. The formative experiment includes the introduction of the obtained methods, the organization of pedagogical conditions for the use of ICT in teaching at the "V.I. Vernadsky Crimean Federal University", conducting intermediate cuts for the diagnosis of mastering the discipline "Mathematics", the formation of students' skills of independent work, the creation of models for the formation of knowledge, skills and abilities of the mathematical process of teaching students to work independently on the base of the usage of information technologies in the learning process. At this stage, the process 
of experimental work and its results are described, methodological proposals for independent work of students are introduced.

The results of mastering knowledge in the basic course of mathematics are monitored by special control modules and tests. The research has shown that the students from the EG demonstrate significant changes in the results of the control module and tests in comparison with the students from the CG. The results were processed using the Cramer-Welch standard. The EG included 59 students $(\mathrm{N}=59)$, and the $\mathrm{CG}-58$ students $(\mathrm{M}=58)$ of the 1 st year of studying at the History and Philology Departments. The characteristic or attributes of the respondent is the number of tasks completed. Let us consider the three levels of knowledge: reproduction (the number of solved problems $>10$ ), production (the number of solved problems $>10$, but 15 proved) and creativity (the number of solved problems $>15)$. In the following table, we will put the number of students according to level (Table 1).

Table 1. Knowledge level.

\begin{tabular}{|l|l|l|l|l|}
\hline \multicolumn{1}{|c|}{$\begin{array}{c}\text { Knowledge } \\
\text { level }\end{array}$} & $\begin{array}{c}\text { CG before the } \\
\text { experiment }\end{array}$ & $\begin{array}{c}\text { EG before the } \\
\text { experiment }\end{array}$ & $\begin{array}{c}\text { CG after the } \\
\text { experiment }\end{array}$ & $\begin{array}{c}\text { EG after the } \\
\text { experiment }\end{array}$ \\
\hline Reproduction & $27(46 \%)$ & $28(48 \%)$ & $24(41 \%)$ & $8(14 \%)$ \\
\hline Production & $23(39 \%)$ & $21(36 \%)$ & $26(44 \%)$ & $39(67 \%)$ \\
\hline Creativity & $9(15 \%)$ & $9(16 \%)$ & $9(15 \%)$ & $11(19 \%)$ \\
\hline
\end{tabular}

Based on the table, we will compose a histogram that can be used to compare the control and experimental groups (Figure 2).
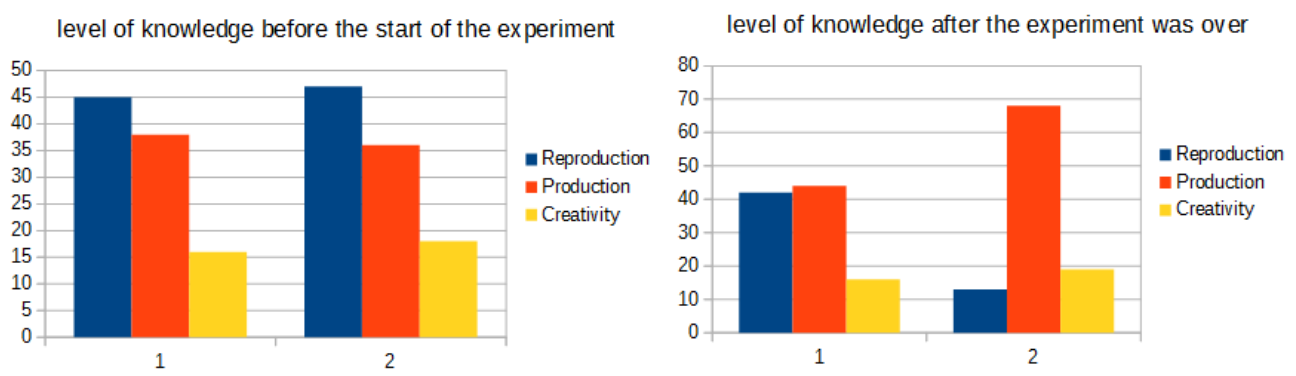

Fig. 2. Results of the experiment.

The analysis of the research results is presented in Table 2.

Table 2. Analysis of the results

\begin{tabular}{|c|c|c|c|c|c|c|}
\hline Term & Group & $\begin{array}{c}\text { The } \\
\text { number of } \\
\text { students }\end{array}$ & $\begin{array}{c}\text { The } \\
\text { number of } \\
\text { “5” }\end{array}$ & $\begin{array}{c}\text { The } \\
\text { number of } \\
\text { “4” }\end{array}$ & $\begin{array}{c}\text { The } \\
\text { number of } \\
\text { “3” }\end{array}$ & $\begin{array}{c}\text { The } \\
\text { average } \\
\text { mark }\end{array}$ \\
\hline \multirow{2}{*}{1} & CG & 59 & 10 & 19 & 30 & 3.66 \\
\cline { 2 - 7 } & EG & 58 & 9 & 22 & 27 & 3.69 \\
\hline \multirow{2}{*}{2} & CG & 59 & 7 & 13 & 39 & 3.29 \\
\cline { 2 - 7 } & EG & 58 & 10 & 23 & 25 & 3.74 \\
\hline
\end{tabular}


Thus, based on the results obtained, it can be concluded that the organization of the educational process using information technologies affects the content, methodology and form of teaching students. These forms of teaching are closely related to the type of presentation and perception of the material by students and teachers.

The results of the experiment showed that it is necessary to organize the independent work of students properly with the help of information technologies and to create new educational tools (including electronic ones) for independent work of students, which will allow not only to form mathematical and technical knowledge, but also to form new educational tools (including electronic ones).

Exploratory experiments help to develop diagnostic tools for the mastering of material in the discipline "Mathematics" and to form students' skills of independent work. As a result, the necessary e-learning tools were created to improve the quality of mathematical education, an independently developed organization of extracurricular work of students was proposed, in connection with which a methodology for organizing students' independent work in mathematics using information technologies was obtained.

Also, the main register of information technologies and a set of software tools for mathematics for students were determined: distance learning courses in Mathematics (based on Moodle); electronic workbooks, spreadsheets for performing mathematical laboratory works; presentation materials in software packages MS PowerPoint, Prezi; software environments for mathematics (EUMC "Live Mathematics", Graph, Deriv, Eureka, Granl); test programs (FreeTest, Uztest), etc.

\section{Conclusions}

The analysis of the methods of teaching Mathematics to students of humanitarian specialties allows us to identify at least three basic concepts. First of all, it is an academic concept that requires a rigorous and demonstrative presentation of specific mathematical facts, accompanied by a large number of examples of analysis. The second concept - it is most appropriate for students of the humanitarian direction to get acquainted with Mathematics along the natural path of its development. This is a kind of course in the history of mathematical science and its creators. This approach is very abstract and has little practical knowledge. The third concept - pragmatic - involves the choice of mathematical material based on the real needs of each specific humanitarian direction. Such an approach is really useful for students of a particular specialty and can arouse their interest in math courses, which will allow them to choose those who want to continue doing math research in the context of their specialty.

The implementation of the above mentioned, according to many experts, requires a long and serious work of professional mathematicians. That is why experts note the absence of successful educational and methodological complexes in Mathematics, focused on a certain humanitarian direction. In our opinion, the third concept of teaching humanitarian students seems to be the most appropriate. This approach seems to be the most relevant in connection with the problems mentioned above: abilities of different levels, interests and quality of pre-university training. It should also be noted that without the use of modern distance technologies, in the case of classroom time's reduction, a simultaneous increase in independent work and a low level of formation of students' independent activity skills, the successful implementation of such courses is impossible. Their use contributes to the improvement of the real educational process in a methodological sense through the use of webinars, interactive teaching methods, express testing and improving the total quality of education. 


\section{References}

1. V.V. Loginova, E.G. Plotnikova, Formation of Professional Competencies of Managers in the Concept of a Profile Approach to Teaching Mathematics, Higher Education Today, 8, 43-48 (2018)

2. The Law of the Russian Federation "On Education in the Russian Federation" dated on December 29, 2012 No. 273 [Electronic resource]. - Access mode: http: //minobrnauki.rf/documents/2974

3. L.P. Martirosyan, A.Yu. Kravtsova, The main directions of Teaching Teachers the Use of Information Technology in Teaching Mathematics, Computer Science and Education, 3, 81-84 (2016)

4. M.V. Soldaeva, Implementation of a Holistic Approach to Teaching Mathematics as a Condition for Achieving Understanding, Izvestiya of Herzen University, 161, 202-205 (2017)

5. V.S. Shipachev, Higher Mathematics, 479 (2017)

6. L.R. Zagitova, Practice-Oriented Mathematical Education, Higher Education in Russia, 8-9, 123-127 (2016)

7. V.A. Slastenin, Pedagogy, 576 (2017)

8. V.A. Uspensky, Mathematical and Humanitarian: Overcoming the Barrier (2018)

9. O.D. Dyachkin, Methodological Aspects of Using a Computer in Teaching Higher Mathematics, New Technologies in Education, 2 (2016)

10. N.N. Gazizova, G.A. Nikonova, N.V. Nikonova, Teaching and Methodological Aid in Mathematics for Students of a Technological University, Higher Education in Russia, 2, 56-61 (2018)

11. V.Yu. Grigoriev, Approaches to Defining the Role of Informatization in the System of Quality Indicators of Higher Education, Informatization of Education, 4, 418-429 (2017)

12. T.V. Kapustina, New Information Technologies for Teaching Mathematical Disciplines at a Teachers' Training University (Based on Mathematica Computer Systems), 92 (2018)

13. F. Bennet, Education \& Future, Educational Technology \& Society, 2(I), 57-60 (2017)

14. D.M. Verneil, Z.L. Berge, Going Online: Guidelines for Faculty in Higher Education, International Journal of Educational Telecommunications, 6, 3 (2016) 